sub-divisions of a multi-coloured square, and reference to these colourcoded boxes is kept up fairly relentlessly throughout the case-studies that follow. As an alternative they also appear in the form of a flow-chart, which ensures that none of the considerations is omitted from our deliberations. The effect of these presentational devices is important. Only if beginners find them useful rather than distracting, and only if they do not mislead readers into supposing that they constitute a method of moral reasoning, can this book be recommended as a lively introduction to medical ethics.

HUGH UPTON, Centre for Philosophy and Health Care,

University College of Swansea.

\section{Philosophy and health care}

Edited by Eric Matthews and Michael Menlowe, Aldershot, Avebury, 1992, viii +229 pages, $£ 35$

This useful collection of papers derives from a conference on medical ethics held in Aberdeen in 1989, but most of the papers have been substantially revised for this publication. Space prevents me from discussing all the papers; I will therefore indicate the scope of the volume and comment on one or two.

The first group of papers is about the rationing of health care. Baruch Brody points to the impossibility of a rational basis for decisions, whether at governmental or at hospital level, and objects to the deceit which tends to be involved in implementing a hospitalbased policy. He advocates encouraging patients themselves to refuse pointless and expensive treatment and/or introducing a voucher system to enable people to choose the kind of health insurance they themselves would favour. These ideas are of course not new, but they are persuasively advocated here. Other papers in this group raise problems about QALYs. S G Potts thinks they are ultimately unjust and tend to advocate euthanasia; Paul T Menzel thinks that while they may represent the scheme which most rational people would consent to (a kind of Rawlsian defence), people might also rationally refuse to put quality enhancement and saving of life itself on the same scale.
A second group of papers concerns the possible rights of fetuses. Here Matti Hayry tackles the thorny problem of how, if at all, a liberal position on abortion can be reconciled with the absolute prohibition of infanticide of normal healthy babies which most people would favour. She argues that prohibiting abortion would be sexist, because it would limit women's 'sovereignty over their bodies' in a way which does not apply to men, whereas prohibiting infanticide is even-handed. This argument is new to me; I do not find it persuasive as stated. If women's sovereignty is to be unlimited, the fetus presumably has no rights; and in that case, there is still a problem in showing how the newborn baby is morally different. True, we can now save it without invading a woman's 'right to choose' - but why must we?

A third group of papers is loosely linked by the topic of letting die, with papers on organ transplants and anencephalic infants; maintaining the brain-dead as 'bioemporia'; criteria for non-treatment of severely handicapped infants; and the social desirability of retaining the prohibition on killing (while allowing some cases of letting die). Christopher Tindall's paper on the brain-dead as bioemporia is striking, but does not seem to me to do justice to the value we place on dignified death and respect for the dead.

In the final paper, Grant Gillett applies Strawson's distinction between objective and reactive attitudes to a discussion of psychiatry. This theme needs clearer handling than it gets in this rather jargon-ridden paper. But it is an important topic, relevant also to the burgeoning activity of counselling. It is refreshing to have one paper at least in a less welltrodden area of medical ethics.

ELIZABETH TELFER, Department of Philosophy, University of Glasgow.

\section{Human needs and the market}

Maureen Ramsay, Aldershot, Avebury, 1992, 221 pages, $£ 35.00$

In this book 'the author maintains that there are universal, objective fundamental human needs, which can be identified empirically, and that the facts about needs have moral and practical implications for action to satisfy them .... Conscious planning to meet needs is advocated since allocation of resources through market mechanisms fails to meet both needs and wants'. There are really two distinct strands to this argument, neither of which depends on the other. The first is whether 'need' is objective and factual, and the second is whether 'need' (when defined) can more effectively be met through market or nonmarket mechanisms. I will consider each strand in turn.

The argument of the book rests on the proposition (page 6) that 'needs may be defined empirically and objectively as means to ends any human being has good reason to pursue, desire or value if they are to act successfully to achieve any end or realise any values, whatever they may be'. It is further argued (page 7) that 'survival is a fundamental human need' as is 'physical and mental health' because 'they are the conditions of any purposive and successful activity' Counter-examples are mentioned but dismissed as exceptions that prove the rule. This leads to the following peculiar statement (page 8): 'We cas choose not to attach any importance te survival and health or to deem othe goals more important, but this does not lessen their importance'. And although the author says (page 7) that she 'stops short of claiming that from the fact that someone needs something we can establish a right or claim for their having it or for claiming that the need ought to be met', this is precisely what she goes on to do (on page 40) when she writes: 'If $A$ accepts that she has prudential obligations to meet her needs, then logically she must accept that all other agents have equally strong prudential reasons for meeting their own'. Thus (page 41): 'this commits me and every other agent to refrain from interfering with other people's attempts to meet their needs and assisting them in meeting them'. No demonstration is attempted of the assertion that all agents have 'equally strong' (as opposed to 'some') reason to preserve their health (including their survival prospects), and in this formulation of the problem it is difficult to see how the members of a society could ever set about the task of priority-setting when all needs cannot be met, which would be a prerequisite for any 'conscious planning to meet needs'.

This brings us to the second strand of the argument, which is marred by some unnecessarily emotional (and 
not very reflective) outbursts about 'the whole disease-ridden edifice of capitalism' (page 137), which totally ignore the even greater prevalence of poor health in the non-capitalist world. The argument that there is great inequality in health, and that much of this flows from unequal access to material resources, and unequal exposure to health hazards of one kind or another, does not require such intemperate polemics. What it requires is a careful analysis of conflicting interests, within individuals as well as between individuals, and a consequent focus on how such conflicts should be adjudicated and the resulting priorities translated into action. Private profit-seeking activity is certainly one of the mechanisms which can be demonstrated to have had (and still to be having) adverse effects upon people's health (for example the production and distribution of cigarettes), but it is misleading to portray this activity as if it were the root of all evil, and to imply that if it were swept away all would be well. Conflicts of interest between individuals, each seeking to meet their own varying needs in their own varying ways, would remain.

If we are to engage in 'conscious planning' to find an efficient and equitable resolution of these conflicting interests, we cannot proceed from the assertion that everyone's needs are equally strong. I think it is this step in her argument which blinds the author to the fundamental problem, which is that of priority-setting. The market solves that problem one way. Like the author, I would like to see it solved a different way, especially with respect to health and health care. What she offers is the suggestion (page 207) that we 'develop a theoretical model of democratically centralised and collective planning where conscious resource allocation renders the satisfaction of fundamental needs for all without imposition.' That could take quite a while, and may even require the end of scarcity. The principles on which we are to base priority-setting in the health field in the meantime are not clear. It is a disappointing book.

ALAN WILLIAMS, Centre for Health Economics, University of York.

\section{Books: information and orders}

If you wish to order or require further information regarding the titles reviewed here, please write to or telephone the BMJ Bookshop, PO Box 295, London WC1H 9JR. Tel: 071 383 6244. Fax: 071383 6662. Books are supplied post free in the UK and for BFPO addresses. Overseas customers should add 15 per cent for postage and packing. Payment can be made by cheque in sterling drawn on a UK bank or by credit card (Mastercard, Visa, or American Express), stating card number, expiry date, and full name. (The price and availability are occasionally subject to revision by the publishers). 